\title{
Miniature atmospheric pressure glow discharge torch (APGD-t) for local biomedical applications*
}

\author{
S. Coulombe $\ddagger$, V. Léveillé, S. Yonson, and R. L. Leask \\ Department of Chemical Engineering, McGill University, Montréal, Québec, \\ Canada
}

\begin{abstract}
The operating parameters of a miniature atmospheric pressure glow discharge torch (APGD- $t$ ) are optimized for the production of excited atomic oxygen, and the effect of the plasma jet on endothelial cells grown in Petri dishes is studied. We first demonstrate the importance of accounting for the effect of the voltage probe used to measure the electrical parameters of the torch on its ignition and operation characteristics. When operated with a main plasma gas flow rate of $1 \mathrm{SLM} \mathrm{He}$ and a power level of $\sim 1 \mathrm{~W}$, the torch shows an optimum in the production of excited atomic oxygen for a $\mathrm{O}_{2}$ flow of $\sim 3.5 \mathrm{SCCM}$ injected downstream of the plasma-forming region through a capillary electrode (i.e., $0.35 \mathrm{v} / \mathrm{v} \% \mathrm{O}_{2} / \mathrm{He}$ ). It is shown that endothelial cells are detached from the Petri dishes surface under the action of the optimized plasma jet and that this effect does not originate from heating and fluid shearing effects. It is postulated that the cell detachment is caused solely by plasma-induced biochemical processes taking place at the cell-substrate interface.
\end{abstract}

Keywords: plasma torch; APGD; nonthermal plasma; glow discharge; biomedical applications.

\section{INTRODUCTION}

Nonthermal ("cold") atmospheric pressure plasma sources offer efficient means for the production of chemically active radicals under low thermal loading conditions [1]. The ability of these devices to operate outside vacuum chambers not only makes the overall operation and installation costs lower, but permits the treatment of mechanically sensitive materials, such as biomaterials and human tissues. Various novel biomedical applications have been explored in the recent past, namely, cell detachment (with or without necrosis) [2], sterilization [3], surface functionalization and patterning [4], and film deposition. Most of those novel applications address large surface-areas, though a local treatment capability is also sought. In the former case, the research and development efforts concentrate mostly on large-area, planar uniform glow discharge sources. So far, uniform glow discharges at atmospheric pressure have been observed only in $\mathrm{He}, \mathrm{Ar}$, and $\mathrm{N}_{2}$, with minute amounts of contaminants added (less than a few v/v \%). In the latter case, plasma "spots" and reduced dimensions plasma torch configurations are exploited, and the glow discharge regime is also sought since it provides the best excitation conditions.

*Paper presented at the $17^{\text {th }}$ International Symposium on Plasma Chemistry (ISPC 17), Toronto, Ontario, Canada, 7-12 August 2005. Other presentations are published in this issue, pp. 1083-xxx.

¥Corresponding author 
A few academic and industrial research groups have developed small-size plasma sources, whose characteristics are suitable for biomedical applications. The "Plasma Needle" developed by Stoffels and colleagues [5] is a unipolar radio frequency (RF) (13.56 MHz) plasma source using helium as the main plasma gas and the surrounding environment as the source of reactive species. It produces a "plasma spot" of $\sim 1 \mathrm{~mm}$ in diameter at power levels on the order of a few hundred $\mathrm{mW}$. Preliminary tests showed the ability of this novel plasma source to locally deactivate bacteria [6] but more interestingly, to cause cell detachment without necrosis [2]. The exact physical and/or biochemical mechanisms responsible for such effects are still unclear, though the participation of UV photons and active species such as excited $\mathrm{O}_{2}$, radicals $\mathrm{O}^{\bullet}$ and $\mathrm{OH}^{\bullet}$ is suspected. The main limitations of the plasma needle are related to the fact that one cannot easily supply the source of reactive species to the plasma-forming zone, and to the inherent electrical coupling with the substrate being treated. Considering those two limitations, the plasma torch configuration offers great promise. Stonies et al. [7] scaled down the microwave $(2.45 \mathrm{GHz})$ plasma torch (MPT) originally developed by Bilgiç et al. [8] to power levels as low as $2 \mathrm{~W}$. A particularly interesting feature of the original design is the use of a concentric central electrode, which permits the injection of the analytes downstream from the plasma-forming region (He or $\mathrm{Ar}$ as plasma-forming gas) and thus, to operate under stable conditions independently of the nature of this additional gas. Though the intended application for this low-power MPT is as an excitation source for atomic emission spectroscopy, the small size of the jet ( $2 \mathrm{~mm}$ length) combined with the low power level and the downstream injection capability make this torch potentially appealing as a biomedical tool. Some small-scale and portable atmospheric pressure plasma sources have already been commercialized as biomedical tools. Amongst the most interesting ones we find the Plasma Skin Regeneration (PSR) device from Rhytec, Inc. [9], the Cold Plasma Coagulation (CPC) device from Söring [10], and the PlasmaPen ${ }^{\mathrm{TM}}$ from PVA Tepla, Inc. [11].

We recently developed a miniature $\mathrm{RF}(13.56 \mathrm{MHz})$ atmospheric pressure glow discharge plasma torch, the so-called APGD- $t$, whose characteristics are well suited for biomedical applications $[12,13]$. In the present article, we report on the main characteristics of the APGD- $t$, on the optimization of the $\mathrm{O}_{2} / \mathrm{He}$ ratio for the maximum production of $\mathrm{O}$ radicals, and preliminary experiments on cell detachment and removal.

\section{CONSTRUCTION AND MAIN CHARACTERISTICS OF THE APGD- $t$}

Figure 1 shows a schematic and a picture of the miniature APGD- $t$. A detailed description is presented in [13]. In essence, the APGD- $t$ construction consists of a quartz confinement tube (i.d. $=2 \mathrm{~mm}$, o.d. $=$ $4 \mathrm{~mm}$ ), a central stainless steel capillary electrode (i.d. $=0.18 \mathrm{~mm}$, o.d. $=0.36 \mathrm{~mm}$ ), and a $2.5-\mathrm{cm}$-long silver epoxy paint deposited on the external surface of the quartz tube serving as ground electrode. The main plasma gas (the plasma-forming gas) is fed in the annulus region delimited by the capillary electrode and the quartz tube, while the source of reactive gaseous species is injected through the central capillary electrode. Such a design feature allows the decoupling of the plasma-forming region from the reactive species production and excitation region and, thus, the consistent and optimum operation of the torch independent of the nature of the source of reactive species. It is suspected that the electron and long-lived metastable atoms produced in the plasma-forming region will act as excitation sources in the afterglow region (i.e., downstream of the plasma-forming region), resulting in a depletion of their respective density. The downstream end of the quartz tube is tapered in order to form a convergent nozzle (i.d. at throat $=500 \mu \mathrm{m}$ ) used to accelerate the plasma stream and form a laminar afterglow plasma jet. The source of reactive species is injected in the nozzle area where the shear stresses are highest (best mixing conditions), and where the afterglow begins. The RF $(13.56 \mathrm{MHz})$ power delivered to the torch is amplitude-modulated using a variable-duty-cycle, square-wave function generator. A homemade inductor of $6.3 \mu \mathrm{H}$ mounted in series between the RF amplifier and the torch is used as impedance matching element. The power delivered to the torch is determined through careful electric probe measurements of the circuit current, torch voltage, and phase angle between both signals. Mass flow controllers 

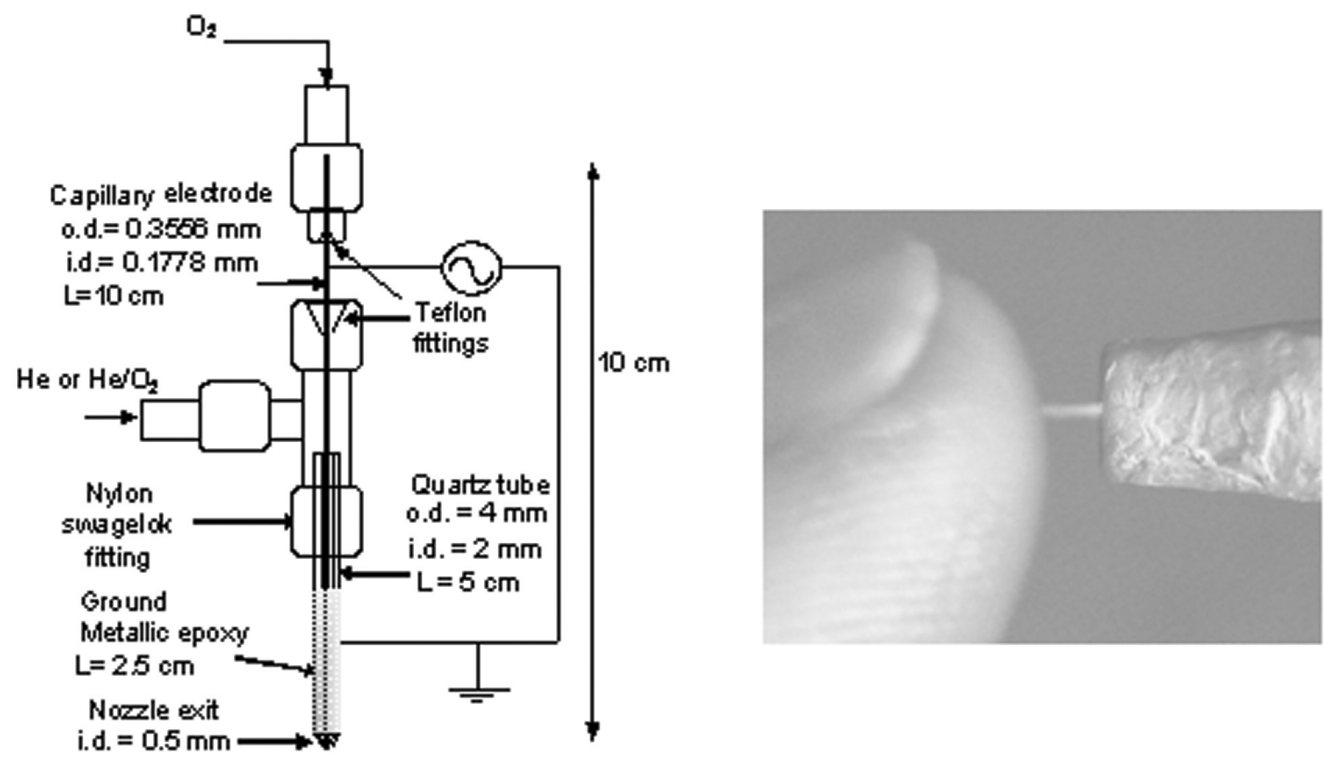

Fig. 1 Schematic of the APGD- $t$ (left) and picture (right) taken with He (1 SLM) at $\sim 1$ W.

are used to regulate the main plasma gas flow rate (He, 0.5 to $1.5 \mathrm{SLM})$ and the gas flow rate through the capillary electrode $\left(\mathrm{O}_{2}, 0-50 \mathrm{SCCM}\right)$. Power level modulation over the $1-5 \mathrm{~W}$ range is achieved by varying the pulse duty cycle from 10 to $50 \%$.

The jet temperature at the nozzle exit ranges from 35 to $120{ }^{\circ} \mathrm{C}$ over this power range. The breakdown voltage in $1 \mathrm{SLM}$ He is low, $\sim 220 \mathrm{~V}$ (from zero to peak voltage), thanks in part to the geometrical amplification of the electric field around the central capillary electrode. Comparatively, the AC breakdown voltage one estimates by extrapolation of the Paschen curve for parallel plate arrangement is $\sim 360 \mathrm{~V}(\mathrm{P}=1 \mathrm{~atm}, \mathrm{~d}=1.8 \mathrm{~mm})[13]$. The power density ranges from 15 to $75 \mathrm{~W} / \mathrm{cm}^{3}\left(\sim 80 \mathrm{~mm}^{3}\right.$ plasma volume) while the reduced energy loading ranges from 60 to $300 \mathrm{~J} / \mathrm{L}$. The APGD- $t$ can thus be classified as a relatively high-energy, density-pulsed RF glow discharge [14].

Figure 2 (top) shows a telemicroscopic image of the He plasma jet ( 1 W, 1 SLM, no $\mathrm{O}_{2}$ in the capillary) discharging into ambient air. The characteristic whitish central cone is associated with the $\mathrm{He}$ emission while the bluish plume surrounding this cone is associated with the excitation of entrained $\mathrm{N}_{2}$ and $\mathrm{O}_{2}$ molecules. The axial distribution of the emission lines suggests the occurrence of several important mechanisms. The presence of the strong $\mathrm{H}_{\alpha}$ line along with the $\mathrm{N}_{2}$ lines suggests a significant entrainment and penetration of (humid) air in the jet immediately at the nozzle exit. The emission from $\mathrm{N}_{2}{ }^{+}(391 \mathrm{~nm})$ suggests that $\mathrm{He}$ metastable atoms $\left(\mathrm{He}_{\mathrm{m}}\right)$ are present far downstream. The faster decay of the $\mathrm{He}(587 \mathrm{~nm})$ line intensity with respect to the $\mathrm{N}_{2}{ }^{+}(391 \mathrm{~nm})$ line suggests that the electron density decays at a much faster rate than the $\mathrm{He}_{\mathrm{m}}$ density. Those metastable species are thus suspected to act as the excitation source far downstream, where the electron-induced excitation has vanished. The axial distribution of the $\mathrm{N}_{2}(337 \mathrm{~nm})$ emission profile is, on the other hand, puzzling since one would expect this emission line profile to peak near the nozzle, as it is the case for $\mathrm{N}_{2}^{+}$. This observation might be experimental evidence for the formation of larger nitrogen molecules in the high-pressure glow region (i.e., $\mathrm{N}_{4}$ ). Such a hypothesis needs to be investigated further using numerical simulations. 


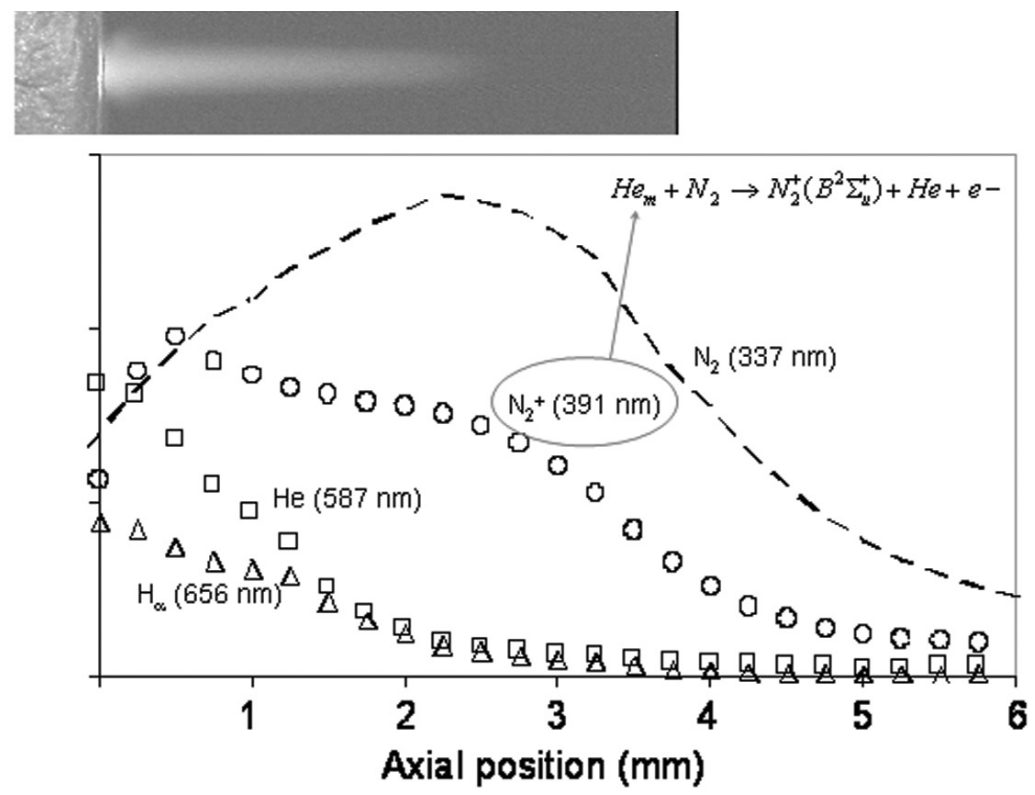

Fig. 2 Telemicroscopic (4 $\bar{\equiv}$ mage of the $\sim 1 \mathrm{~W}$ He (1 SLM) plasma jet (top) and axial distribution of the line-ofsight integrated relative inturity of selected emission lines.

\section{IGNITION AND STABILIZATION}

By its construction, the APGD- $t$ is a concentric-electrode capacitor of capacitance value approximately equal to $C_{\mathrm{T}}{ }^{\text {cold }} \sim 1.5 \mathrm{pF}$ in the absence of the plasma ("cold" state). The APGD- $t$ thus represents a high capacitive impedance load $\left(X_{\mathrm{C}}=-\left(2 \pi f C_{\mathrm{T}}{ }^{\text {cold }}\right)^{-1}=-7824 \Omega\right.$ at $\left.f=13.56 \mathrm{MHz}\right)$, larger in magnitude than the capacitive impedance of common passive voltage probes (e.g., Tektronix P6139A: $C_{\mathrm{P}}=8 \mathrm{pF}, R_{\mathrm{P}}=$ $10 \mathrm{M} \Omega, Z_{\mathrm{P}}=0.215-1467 \mathrm{j} \Omega$ at $f=13.56 \mathrm{MHz}$ ). This particularity of the torch has two important consequences: (i) The circuit current leads the torch voltage signal by a phase angle approaching $90^{\circ}$, bringing considerable uncertainties on the power determination from probe measurements. (ii) Probe loading effects must be considered in the design of the electric circuit, and in the calculation of the APGD- $t$ electrical parameters (resistance, capacitance, and resistive power dissipation). As an illustrative example, consider the calculations for the ringing conditions of the $R L C$ circuit formed by the torch, inductor, and voltage probe (Fig. 3). The "cold" conditions are modeled by replacing $C_{\mathrm{T}}$ and $R_{\mathrm{T}}$ (the torch capacitance and resistance) by $C_{\mathrm{T}}$ cold only. The experimentally determined values of $C_{\mathrm{T}}$ and $R_{\mathrm{T}}$ obtained in [13] are used for the calculations.

We obtain theoretical resonant circuit conditions at $f=20 \mathrm{MHz}$ for the "cold" situation. Note here that those calculations do not take into account any additional parasitic capacitors and inductors and ,thus, the resonant frequency does not coincide with the experimental one (13.56 MHz). The calculated resonance frequency shifts to $\sim 16 \mathrm{MHz}$ when the glow discharge is present in the gap. At this frequency, the voltage applied to the torch is approximately six times larger than the source voltage. Note that the amplification factor at this specific frequency is higher than the one observed under "cold" conditions. When the probe is removed from the model circuit, a flattening of the frequency response is observed, but more importantly, the voltage amplification factor near $f=13.56 \mathrm{MHz}$ becomes very small ( 1.2). Though idealized, those calculations reveal the significant effect of the passive voltage probe on the torch operation. In fact, we observed experimentally that the inductance must be increased substantially (i.e., doubled) in order to achieve proper ignition and operating conditions without the passive voltage probe. This brief study of the effect of the electrical probe on the circuit operation reveals the signifi- 


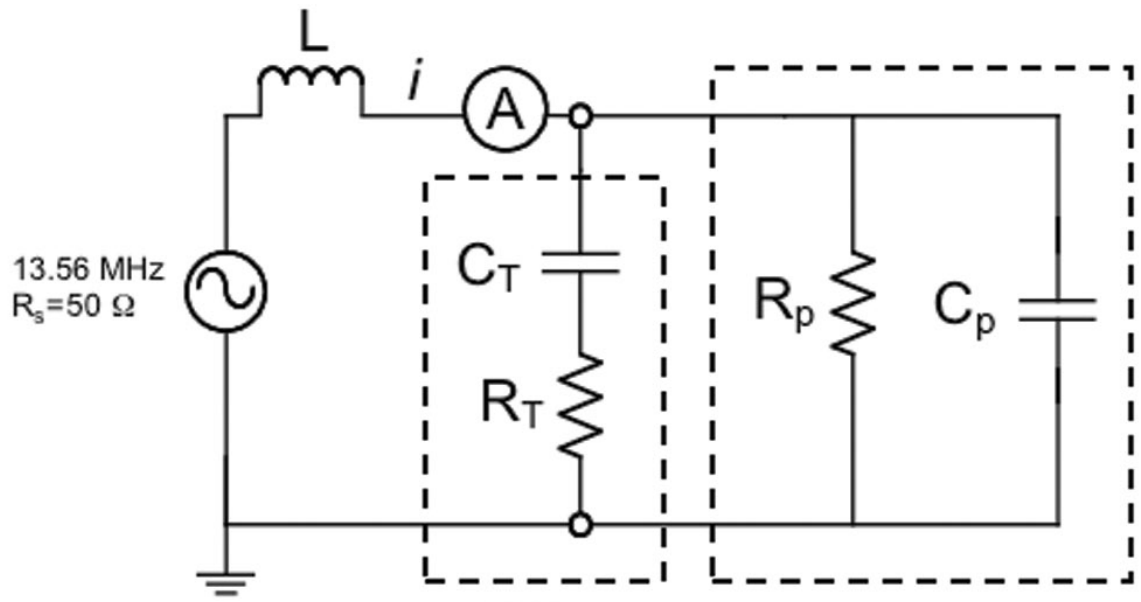

APGD- $t \quad$ Passive voltage probe

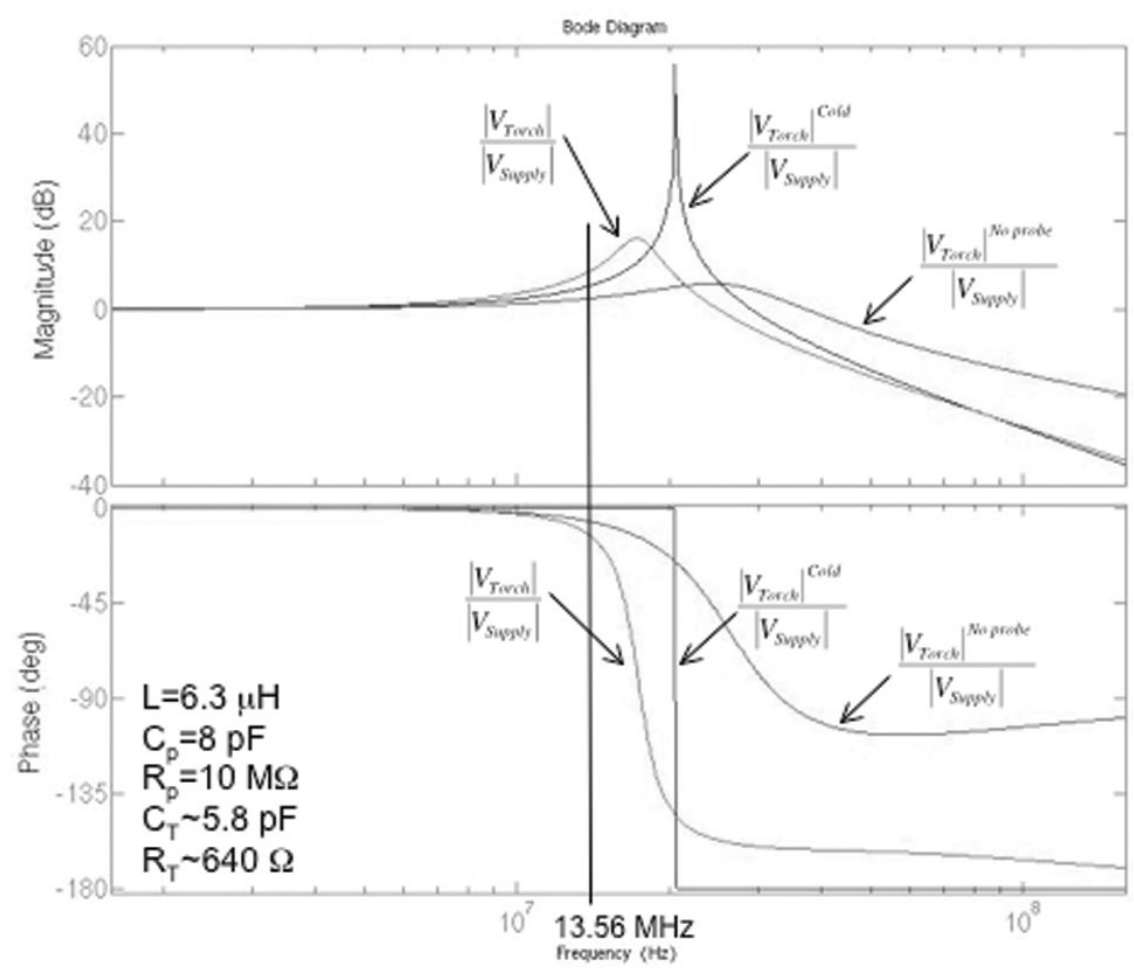

Fig. 3 Schematic of the electrical circuit (top) and Bode diagrams of the voltage amplification factor.

cant coupling effect that exists. Such reality is, unfortunately, not always reported in other studies using similarly large capacitive impedance load.

\section{OPTIMIZATION OF THE ATOMIC OXYGEN PRODUCTION}

Figure 4 shows the effect of the $\mathrm{O}_{2}$ flow rate in the capillary electrode on the line-of-sight integrated relative intensity of the atomic $\mathrm{O}(777 \mathrm{~nm})$ line and jet temperature at the nozzle exit. The torch power and He flow rate were kept at constant values of $\sim 1 \mathrm{~W}$ and $1 \mathrm{SLM}$, respectively, while the tip of the 
capillary electrode was recessed from the nozzle exit plane by $\sim 200-300 \mu \mathrm{m}$. Figure 4 shows a maximum in the $\mathrm{O}(777 \mathrm{~nm})$ line emission for a $\mathrm{O}_{2}$ flow rate of $\sim 3.5 \mathrm{SCCM}$, whose flow rate value corresponds to a $\sim 0.35 \mathrm{v} / \mathrm{v} \% \mathrm{O}_{2} / \mathrm{He}$ gas composition (assuming a perfect mixing downstream of the injection point). The jet temperature also shows a maximum at the same flow rate, though it is not as pronounced. We attribute the coincidence of both peaks to the optimum conditions for the production of $\mathrm{O}$ from the dissociation of $\mathrm{O}_{2}$, leading to a peak in both the density of $\mathrm{O}$ and the thermal conductivity of the gas mixture (i.e., heat-transfer rate to the thermocouple). Seen this way, the occurrence of both peaks at the same $\mathrm{O}_{2}$ flow rate is unavoidable, and represents a limitation for biomedical applications: the conditions for the maximum production of atomic oxygen are those that will lead to the highest thermal load to the sample being treated. Consequently, tradeoffs on the treatment time will have to be made.

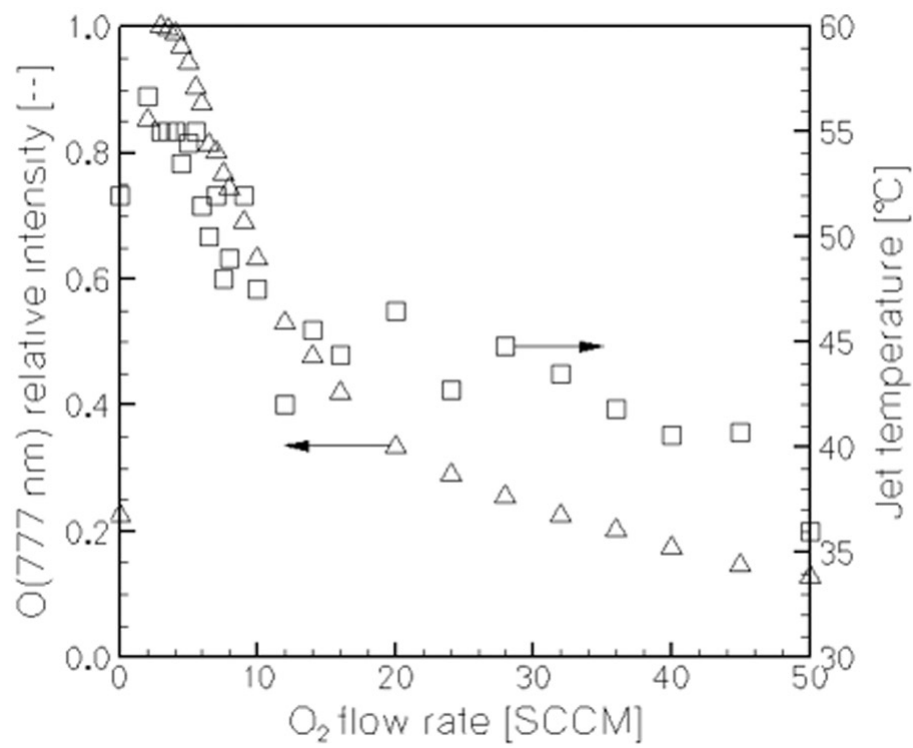

Fig. $4 \mathrm{O}(777 \mathrm{~nm})$ relative intensity and jet temperature at the nozzle exit vs. $\mathrm{O}_{2}$ flow rate.

It is also important to report that the structure of the jet remained essentially unchanged over this range of $\mathrm{O}_{2}$ flow rates (results not shown here) and, thus, that little quenching of the jet occurs. Conversely, the injection of less than $1 \mathrm{v} / \mathrm{v} \% \mathrm{O}_{2}$ mixed with the plasma-forming leads to a drastic quench of the jet [13] and, consequently, to a significant reduction in the $\mathrm{O}(777 \mathrm{~nm})$ emission line intensity. Such a phenomenon is observed in another RF $(13.56 \mathrm{MHz})$ dielectric barrier discharge configuration using $\mathrm{O}_{2} / \mathrm{He}$ mixtures [15]. In this later configuration, the threshold concentration is $4 \mathrm{v} / \mathrm{v} \%$ $\mathrm{O}_{2} / \mathrm{He}$. We attribute the quenching of the $\mathrm{O}(777 \mathrm{~nm})$ line emission to the loss of the glow discharge uniformity in the plasma-forming region, which in turn is associated with the formation of filamentary discharges.

\section{CELL DETACHMENT}

In order to assess the suitability of the APGD- $t$ as a tool for biomedical applications, we initiated a series of experiments aimed at studying cell detachment under the action of the plasma jet. Human aortic endothelial cells (HAAE-1, ATCC, Manassas, VA) were cultured in F12-K medium (ATCC) supplemented with $10 \%$ fetal bovine serum (ATCC), $100 \mu \mathrm{g} / \mathrm{mL}$ penicillin (ATCC), $100 \mu \mathrm{g} / \mathrm{mL}$ streptomycin (ATCC), $0.1 \mathrm{mg} / \mathrm{mL}$ heparin (Sigma-Aldrich, Oakville, ON), and $0.03 \mathrm{mg} / \mathrm{mL}$ endothelial cell growth 
supplement (Becton-Dickinson, Bedford, $\mathrm{MA}$ ) at $37{ }^{\circ} \mathrm{C}$ in a $5 \% \mathrm{CO}_{2}-95 \%$ air-humidified incubator. Cells were seeded into $60 \times 15 \mathrm{~mm}$ cell culture Petri dishes (Corning, Corning, NY) and allowed to reach confluence. The APGD- $t$ was mounted on a stage, allowing precise vertical displacements. Prior to treatment, the vertical axis was zeroed in relation to an empty Petri dish in order to calculate the distance between the nozzle end and the cells' exposed plane. The APGD- $t$ was operated using 1 SLM He as the plasma-forming gas and $3 \mathrm{SCCM} \mathrm{O}$ through the capillary electrode $\left(0.3 \mathrm{v} / \mathrm{v} \% \mathrm{O}_{2} / \mathrm{He}\right.$ corresponds to the near optimum gas mixture for the production of excited atomic oxygen). The torch power was $\sim 1 \mathrm{~W}$, giving rise to a jet temperature in the cells' plane of $\sim 40{ }^{\circ} \mathrm{C}$. During the plasma treatment, cells were taken out of the incubator and the height of the media adjusted to $1 \mathrm{~mm}$. Cells were positioned at the specified distance from the tip of the torch nozzle, and the Petri dish moved by hand under the lit torch, creating a treatment path in the cells. The power to the torch was then turned off, leaving the gas flow on, and a second path was made through the cells to distinguish the effect of the gas flow on cell detachment. The treated cells were then stained with crystal violet (Becton-Dickinson), rinsed twice with PBS (Fisher, Whitby, ON), and fixed with formalin (Fisher). The cells were immediately examined under the Leica DM IL inverted light microscope and photos were taken using the Leica DC300 digital camera system. The $\mathrm{pH}$ of the media was monitored with a phenol red indicator, and no change was noticed upon exposure to the plasma jet.

Figure 5 shows the effect of both gas (a) and plasma (b) treatment on the endothelial cells for exposure times of $\sim 0.15 \mathrm{~s} /$ cell. One sees that the plasma jet causes the detachment of cells from the Petri dish in a clear trace approximately $0.5 \mathrm{~mm}$ wide, the width of the plasma jet at the nozzle exit. The borders of this trace are very sharp, with the cells at the very edge of the border appearing healthy and unaffected as can be seen at higher magnification (Fig. 6). Unfortunately, it is impossible at this point to quantify the extent of cell detachment since the uncertainty on the cell counts would be too large. Nevertheless, a significant cell detachment is observed. The effect of gas alone flow was evaluated during each experiment to ensure that the cells were not being mechanically detached due to the shear stresses imposed by the high gas flow. Additionally, due to the short exposure time to the plasma flow, cell dehydration is not likely to be a factor influencing cell detachment. In fact, the covering media is only momentarily displaced by the jet, leaving the cells uncovered for only a few seconds. Figure 5a demonstrates that the cells exposed exclusively to the gas flow (plasma off) reveal minimal detachment. The effect of gas temperature alone was tested by exposing the back side of the glass Petri dish to the plasma jet until the temperature at the cells' surface became similar to the one observed under the nominal treatment conditions. No changes to the cells were observed by inspection through the microscope. Those observations seem to suggest that the observed phenomena originate from biochemical processes induced by the plasma-cells interactions. 
(a)
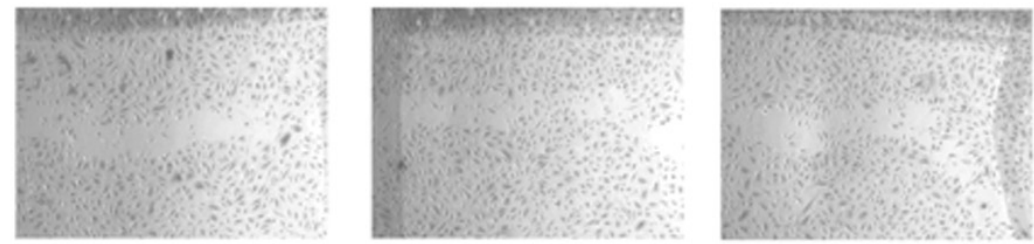

(b)
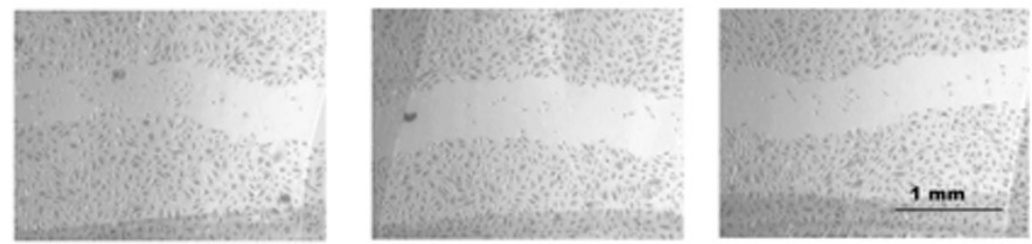

Fig. 5 Effect of gas (a) and plasma (b) treatment on HAAE-1 cells with a distance between the nozzle and cells of $2 \mathrm{~mm}$, and a media height of $1 \mathrm{~mm}$. Cells have been stained with crystal violet for visualization purposes (25X).

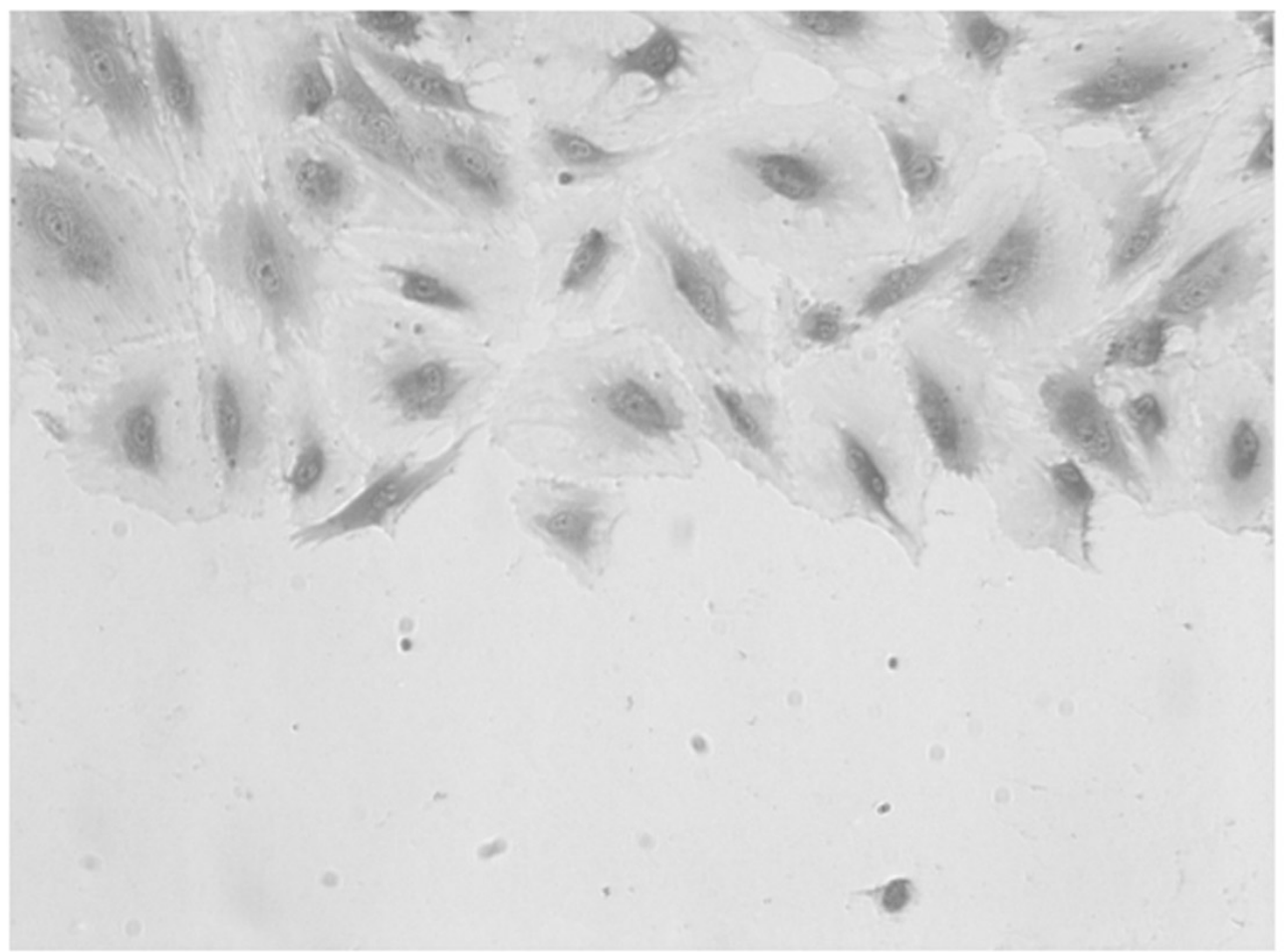

Fig. 6 Cells at the edge of the plasma treated area appear healthy (100X). 
Reactive oxygen species (ROS) such as the $\mathrm{OH}^{\bullet}$ radical, hydrogen peroxide, and singlet oxygen are known to be able to initiate lipid peroxidation, protein degradation, and apoptosis of the cell. The $\mathrm{OH}^{\bullet}$ radical is very reactive, and its short lifetime ( ns) [16] does not suggest a significant penetration through the cell membrane. The chemical attack by this radical would be focused on the exterior of the cell, oxidizing the lipids in the cell membrane and disrupting the adhesion proteins of the cell. The $\mathrm{OH}^{\bullet}$ radical can be produced in the jet due to the presence of humidity in the laboratory air, and could also result from the dissociation of water used in the cell coverage media. Singlet oxygen has a much longer lifetime and can diffuse through the cell membrane [17]. It is the primary agent in photodynamic therapy, a photosensitizing cancer treatment, where it induces cytotoxicity within the cell [18]. Entrainment of air in the plasma jet creates reactive nitrogen species (RNS), which are also known to cause damage to the cell. The ROS and RNS are likely to initiate many oxidation reactions with the cell, resulting in cell detachment.

\section{CONCLUSIONS AND OUTLOOK}

We presented the general characteristics of a miniature $\mathrm{RF}(13.56 \mathrm{MHz})$ atmospheric pressure glow discharge torch, the so-called APGD- $t$, and demonstrated its suitability for use as a biomedical tool. The miniaturized size of the plasma jet, $500 \mu \mathrm{m}$ o.d. at the nozzle exit, combined with the low-duty-cycle amplitude modulation of the RF power enables the local treatment capability within the thermal limits imposed by biomedical applications $\left(<50^{\circ} \mathrm{C}\right)$. We first reported on the difficulties one encounters with the impedance matching and the monitoring of the electrical parameters of such torch (resistance, capacitance, and resistive power dissipation) due to the high capacitive load it represents. Our preliminary optimization study with a $\mathrm{O}_{2} / \mathrm{He}$ mixture revealed that a maximum in atomic oxygen emission $(\mathrm{O}(777 \mathrm{~nm}))$, whose signal is taken as a measure of the $\mathrm{O}$ concentration in the jet, is reached at $\sim 3.5 \mathrm{SCCM} \mathrm{O}_{2}$ fed in the capillary electrode when the plasma-forming gas flow is 1 SLM He $\left(\sim 0.35 \mathrm{v} / \mathrm{v} \% \mathrm{O}_{2} / \mathrm{He}\right)$, and the torch power is $\sim 1 \mathrm{~W}$. Preliminary experiments conducted with endothelial cells demonstrated the ability of the APGD- $t$ to detach cells from a Petri dish. Our preliminary detective work seems to indicate that the detachment mechanism takes its roots in biochemical processes induced by the presence of the plasma.

Other investigations are in progress in order to determine if the cells detached from the Petri dishes are still alive and further assess the suitability of the APGD- $t$ for other biomedical applications, namely, local sterilization, local cell lysis, local deposition of temporary organic films, and local surface functionalization for grafting and patterning. The plasma and biomedical engineering communities are encouraged to develop joint research and development efforts in order to elucidate the basic biochemical and physical mechanisms participating in the plasma-biological surface interactions, and to further develop this promising technology.

\section{ACKNOWLEDGMENTS}

The authors wish to thank the ISPC 17 conference organizers for the invitation made to S. Coulombe to present this research project, and the Natural Sciences and Engineering Research Council of Canada (NSERC), the Fonds Québécois sur la Nature et les Technologies (FQRNT), and the Department of Chemical Engineering, McGill University (EUL Funds) for the financial support. The authors also wish to thank Prof. A. Ricard for his suggestion on the possible formation of larger nitrogen molecules. 


\section{REFERENCES}

1. A. Fridman, A. Chirokov, A. Gutsol. J. Phys. D: Appl. Phys. 38, R1 (2005).

2. I. E. Kieft, D. Darios, A. J. M. Roks, E. Stoffels. IEEE Trans. Plasma Sci. 33, 771 (2005).

3. M. Laroussi. Plasma Process. Polym. 2, 391 (2005).

4. P.-L. Girard-Lauriault, F. Mwale, M. Iordanova, C. Demers, P. Desjardins, M. R. Wertheimer. Plasma Process. Polym. 2, 263 (2005).

5. E. Stoffels, A. J. Flikweert, W. W. Stoffels, G. M. W. Kroesen. Plasma Sources Sci. Technol. 11, 383 (2002).

6. R. E. J. Sladek, E. Stoffels. J. Phys. D: Appl. Phys. 38, 1716 (2005).

7. R. Stonies, S. Schermer, E. Voges, J. A. C. Broekaert. Plasma Sources Sci. Technol. 13, 604 (2004).

8. A. Bilgiç, C. Prokisch, J. Broekaert, E. Voges. Spectrochim. Acta B 53, 773 (1998).

9. Rhytec, Web site: <www.portraipsr.com>.

10. Söring, Web site: <www.soering.com>.

11. PVA Tepla, Web site: <www.pvatepla.com>.

12. S. Coulombe, V. Léveillé. "Low-Power Atmospheric Pressure Glow Discharge Torch", U.S. Provisional Patent Application US60/705,443, 5 August 2005.

13. V. Léveillé, S. Coulombe. Plasma Sources Sci. Technol. 14, 467 (2005).

14. A. P. Napartovich. Plasmas Polymers 6, 1 (2001).

15. J. Park, I. Henins, H. W. Herrmann, G. S. Selwyn. J. Appl. Phys. 89, 15 (2001).

16. C. Batandier, E. Fontaine, C. Kériel, X. M. Leverve. J. Cell Mol. Med. 6, 175 (2002).

17. J. Moan. J. Photochem. Photobiol. B: Biol. 6, 343 (1990).

18. F. S. De Rosa, M. V. L. B. Bentley. Pharm. Res. 17, 1447 (2000). 